\title{
A Summer Working in Spain
}

RYAN BROUGH

Ryan Brough is a senior in the BCRP program, City and Regional Planning Department, Cal Poly.

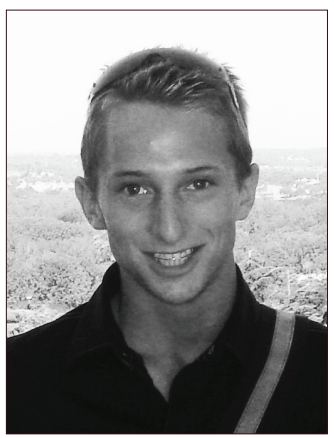

In the Summer of 2008, Ryan Brough took the most out of his vacation with family friends in the beautiful Cullera, Spain. He got an internship with a real estate development company in Valencia, and was able to lear a lot about local planning and construction practices. He also learned about the Spanish culture and their very urban lifestyle.

\section{Culture Shock}

In summer of 2008 I had the once in a lifetime opportunity to travel to Spain and spend eight weeks experiencing a culture so different from my own. My first morning in my new flat in the city of Cullera, I awoke in and walked into my living room I opened my windows and looked out over the city and it hit me, I was no longer in America; Valencia would be my home for the next eight weeks. It was a surreal feeling; I immediately grabbed my camera and took pictures to remember that moment. There is no comparison to make in the United States; the people, culture, and built environment warrant endless exploration. For the first few days I was completely overwhelmed but it was not long before I felt right at home.

I spent my first day getting a tour of the city from a family friend and owner of a real estate development company based out of Valencia, Spain, Nagada Arquitectura. A typical tour guide never could have given me that perspective. His company has restored many structures throughout the city, including some of the historical buildings in the downtown. Seeing these structures with him also gave me the opportunity to ask him questions about the process of development in Spain and that was where the real learning began. On some occasions, I was able to also gain entrance into the structures and see them up close and personal.

\section{Professional Experience}

In the United States planning and architecture are always imitating what they think history should look like to achieve a certain nostalgia. Spain appeared to have some similar methods of imitation, but by

Figure 1 in large, the country embraced their authentic history. In Spain, I found that even in the more recently

View taken from the residence in the beach city of Cullera, Spain. (photo by Ryan Brough)

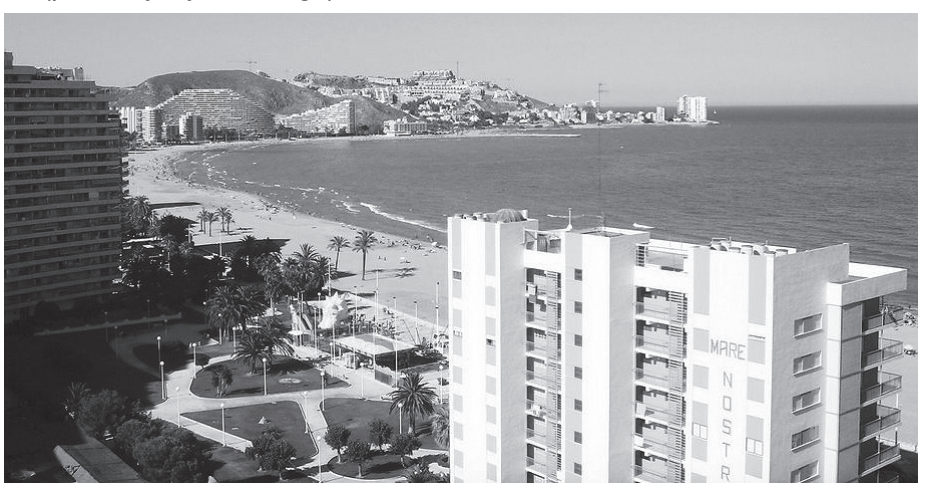

The City of Moncofa sits roughly thirty miles north of Valencia. The project consists of 101 condominiums on the coast with beach and ocean views. Prior to going to any meetings or site visits for the project, I reviewed the architectural plans. This gave me the basic structural makeup of the project and the detail of the project down to the material boards. The financial statements and pro-formas were also made available for my review; however, they scarcely resembled anything we learned in school. These pro-formas were written in great detail and with direct correspondence to the phasing plan. A financial cushion was also built into 
the budget for the unavoidable speed bumps that the project would hit. The architectural and financial review of the project gave me an opportunity to see basic site, structural, financial opportunities, and constraints with full transparency. This was one of the most valuable experiences because I got to see proprietary project information that most companies never would have revealed.

At this point I also received the opportunity to speak with the architect on why specific decisions were made and what alternatives were considered. This open dialogue between all the players was invaluable to understanding how the project had progressed to the construction phase. Listening to all of the reasoning behind each decision gave context to the whole project; this also made understanding the whole process much easier.

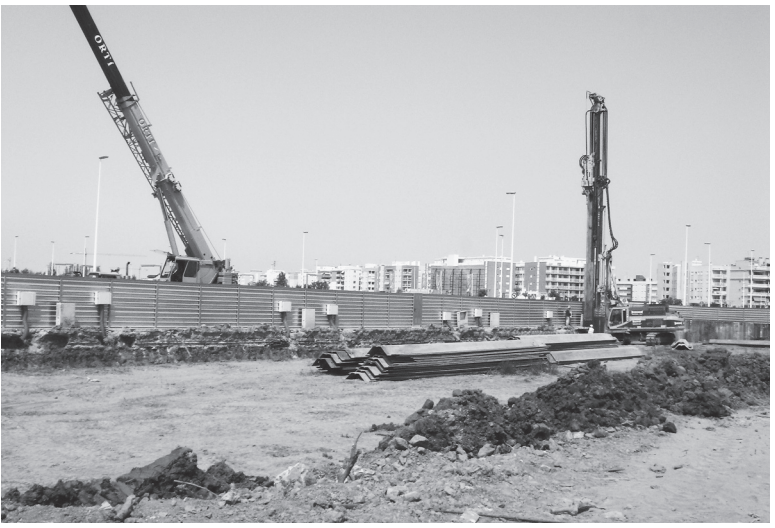

Figure 2

The construction site in Moncofa, Spain. (photo by Ryan Brough)

out to set the foundation for what would become the subterranean parking. On that same day I also attended a marketing meeting for the project. In our curriculum, we often deal with the development phase of projects, but rarely do we get the opportunity to see what happens after the structure is built. Attending this meeting with the developer and his sales team gave me the opportunity to see post- construction work.

\section{Planning Spotlight - Turia Riverbed}

If there is one element in the Valencia landscape that stands out and is unique to few cities, it would be the Turia Riverbed. This feature is so prominent, widespread, and innovative that it is impossible to miss. Although many water features are present in this space, there is no river.

In Turia's riverbead, a spine creeps through the center of all major cultural centers.In the 1950's, the River Turia flooded and in an effort to prevent future flooding and any additional damage to the various districts, the parliament approved the Plan Sur to divert the river elsewhere.This left a riverbed full of rich soils perfect to nurture the garden that would come thereafter.

Since the approval of that plan, the space has evolved to be a social center. Before the sun comes up, the space comes alive with runners, and continues long after the sun goes down. Similar to Central Park in New York, the space in Valencia is not only a great place for running, but also for watching people throughout the day. For me, it became an especially wonderful place to run in the mornings. Every day I would find a new little garden or nook. After eight weeks in the city, there is still plenty to explore the next time I return.

By default, the space is sunken lower than the rest of the city because of its historical use; this geographical quality also makes the space startlingly quiet and serene; sound waves from the city bounce over the lower riverbed elevations.

This enables every visitor to find their own special secluded place, even in the the middle of the day. There is also a spectacular tree canopy, which has grown over the last fifty years. The canopy is so extensive, that visitors can get caught up in nature and forget that they are in the third largest city in Spain. This natural backdrop sets the scene for countless other places.

Not only are there attractions for the children, but there are attractions for entire families as well. 


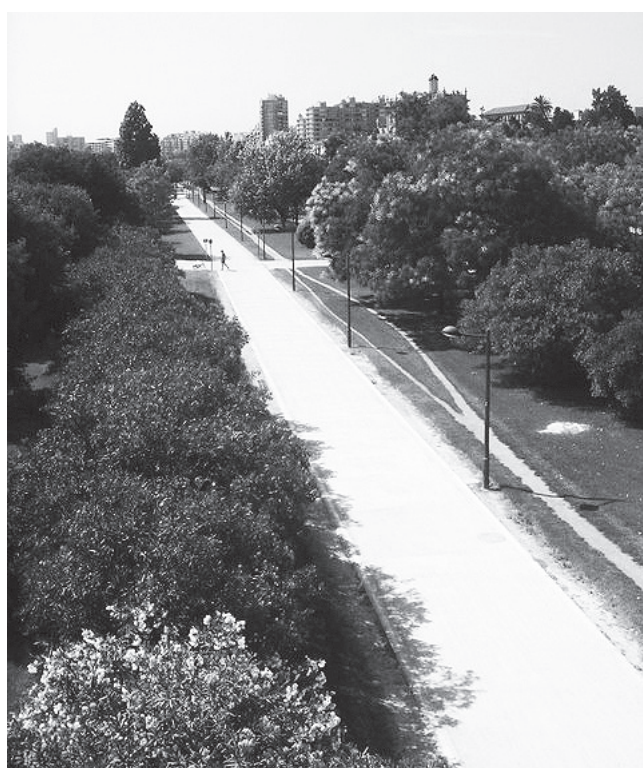

Figure 3

The main pedestrian arterial in the Turia Riverbed Park, Valencia. (photo by Ryan Brough)
There are multiple jungle gym park sets and all the typical play equipment children expect and some they wouldn't that double as great pieces of public art. For families of all ages cafes are dotted along the length of the riverbed where you can get an afternoon snack or a cool cup of orchatta, a traditional drink made from the chufa plant.

\section{Spain - Lifestyle}

Americans visit their history, while Europeans live with their history. This was made ever so clear to me this summer while I lived in Valencia, a city with a rich history that is infused into every facet of life. It is especially evident in the historical district of the city where the new and old are seamlessly woven together. In a city founded before Christ, an extensive and continually growing subway system (named Metro) connects the historic and modern pieces of the city. This Metro system is used everyday by most city residents namely because it is simply the fastest way to commute. This is not a new concept for Europeans, but for me, coming from the personal vehicle dominated California, it was. I very quickly warmed up to the idea of public transportation and used it nearly everyday.

Valencia's regional role makes it the cultural center. Within the city limits exists parks, countless museums, L'Oceanogràfic, (the largest aquarium in Europe) and multiple sports complexes, including a new under construction soccer field. These cultural destinations made the daily exploration of Valencia sure to never disappoint. During the typical day I was able to walk the city and take advantage of most of the cultural destinations. At night the opera house and concert halls opened there doors with a diverse schedule of performers. However, on the weekends, we were off to the summer home.

In Spain, virtually everyone takes their vacation in either July or August. During this time everyone escapes to their summer homes and my family friends are no different. Every weekend I went to Cullera Spain, I learned what Spanish living was all about When I went to the porch off of my bedroom and saw the view pictured below, it became clear to me how well the Spanish culture really embraces life. They take pleasure in life in a way incomparable to anyone I can recall in the United States. Everything is a family affair and no one is ever left out. I was shocked every night as I peered over the beach from my room and saw how many families with young children would be out strolling on the boardwalk until midnight. The outdoor spaces come to life and people interact with genuine interest and concern.

In Spain they work to live. When we were at the summer house, work was not on the minds of anyone. It was all about the food, family, friends, the afternoon siesta, and the nightly festivity. The food was always in mass quantities and unparalleled to any other I have ever had; I cannot begin to explain it. Being on the Mediterranean Coast, seafood was in nearly every meal. Even lunch was an experience not to be rushed. The meal would usually be a two hour event with long discussion and plenty of beverages. Food is not only eaten to feed your hunger but also your soul, there is history and culture in every dish. Even where they eat is a spectacle. Most Saturdays and Sundays we would dine on the bluff overlooking the family's orange grove seen below.

\section{Conclusion}

Spain hardly gets enough accolades for what it brings to the international traveler. Its rich history and 
its people's generosity make all visitors feel right at home. For the architect planner or spectator of the arts both physical and otherwise the city leaves something for endless return trips. Most importantly, a trip to Europe, especially Spain gives a look into another culture which fosters reflection on our own.

Living, studying, and working abroad are experiences every student should take advantage of while in college. The personal and professional growth that occurs cannot be created in a classroom setting and is truly irreplaceable.

Figure 4

Center for Science and Arts located in the Turia Riverbed Park, Valencia. (photo by Ryan Brough)

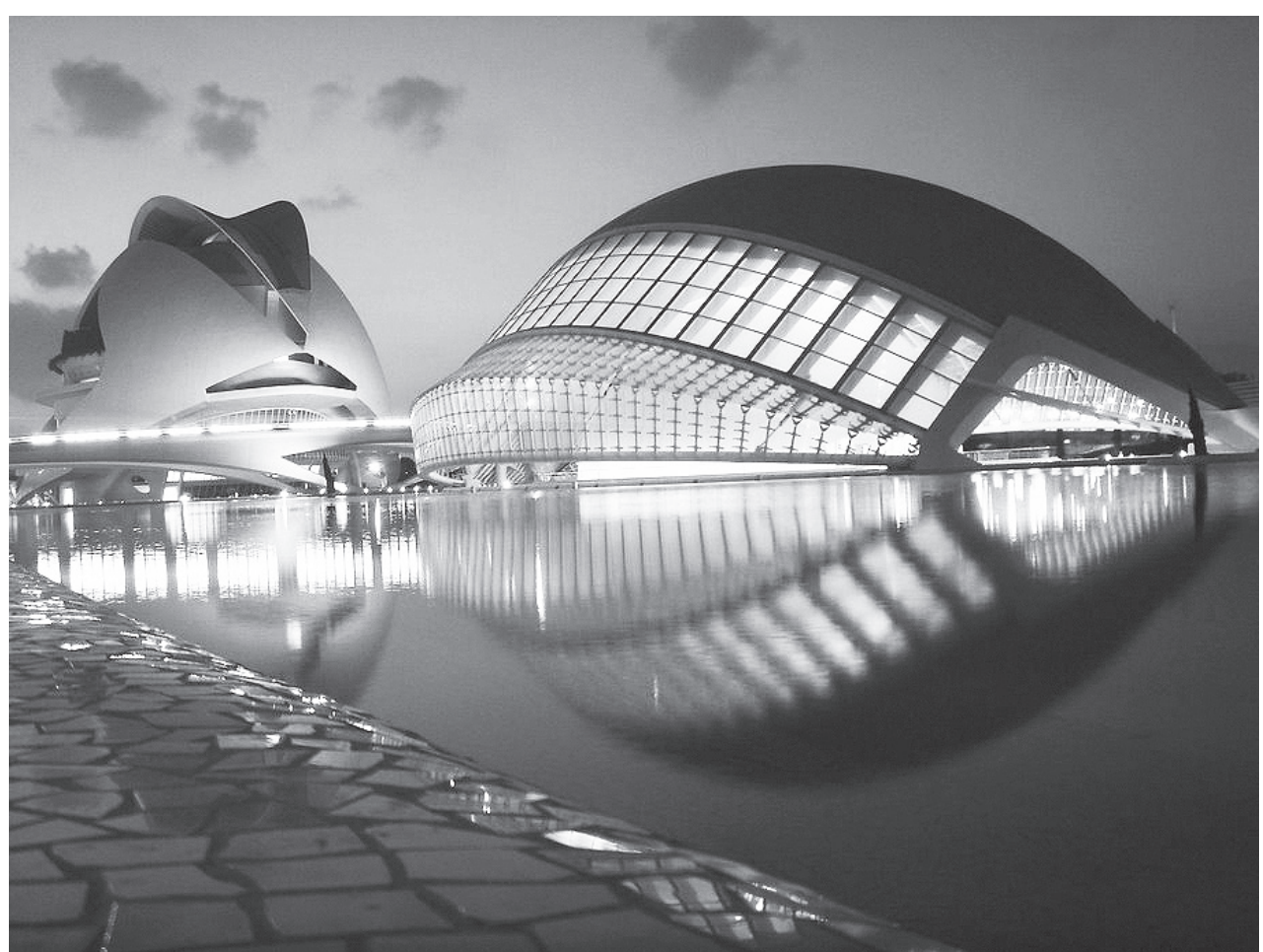

